\title{
Pengembangan Sistem Informasi Keberadaan Dosen Menggunakan Model Prototype
}

\author{
Evi Dwi Wahyuni ${ }^{1}$, Wahyu Andhyka Kusuma ${ }^{2}$, Ahmad Zaky ${ }^{3}$, Zamah Sari ${ }^{4}$ \\ ${ }^{1}$ Teknik, Informatika, Universitas Muhammadiyah Malang, Malang, Indonesia \\ Email: 1,*evidwi@umm.ac.id, ${ }^{2}$ kusuma.wahyu.a@umm.ac.id, ${ }^{3}$ ahmadzakym22@gmail.com, \\ zamahsari@umm.ac.id
}

\begin{abstract}
Abstrak-Masalah yang dihadapi di jurusan Informatika Universitas Muhammadiyah Malang, mahasiswa sering kali menanyakan keberadaan dosen kepada staff administrasi sebelum dilihat diruangannya. Hal ini cukup menyita waktu dan mengganggu pekerjaan. Penelitian terdahulu telah dilakukan untuk mengatasi permasalahan tersebut dan hanya sampai pada perancangan prototype. Tetapi, prototype yang telah dibuat, sudah pernah ada sistem serupa yang diterapkan di jurusan namun tidak berjalan lancar karena tidak semua dosen mau untuk menginputkan data ke sistem. penelitian ini memberikan solusi agar sistem yang dibuat dapat diterima dan sesuai dengan apa yang dibutuhkan pengguna. Penelitian ini telah berhasil menerapkan metode pengembangan prototype untuk pengembangan sistem informasi keberadaan dosen. Dengan tahapan pengembangan dimulai dari inisialisasi, perancangan prototype, production, evaluasi pengguna dan pengujian. Pengujian sistem terhadap 11 poin kebutuhan fungsional juga telah berhasil dioperasikan dengan baik dan diperoleh hasil yang sesuai dengan kebutuhan.
\end{abstract}

Kata Kunci: Sistem informasi keberadaan dosen, model prototype, pengujian blackbox.

Abstract-Problems faced in the Department of Informatics, University of Muhammadiyah Malang, students often ask the existence of lecturers to administrative staff before being seen in their room. This is quite time consuming and disrupts work. Previous research has been done to overcome these problems and only to the design of prototypes. However, the prototype that has been made, there has been a similar system that was applied in the department but it did not run smoothly because not all lecturers wanted to input data into the system. This research provides a solution so that the system can be accepted and in accordance with what is needed by the user. This research has successfully applied the prototype development method for the development of the Lecturer Existence Information System. With the development phase starting from initialization, prototype design, production, user evaluation and testing. System testing of 11 functional requirements points has also been successfully carried out and obtained results in accordance with the needs.

Keywords: Information systems for the existence of lecturers, prototype model, blackbox testing.

\section{PENDAHULUAN}

Pada jurusan teknik informatika Universitas Muhammadiyah Malang, mahasiswa biasanya bertanya pada staff administrasi jurusan mengenai keberadaan dosen. Staff administrasi bertugas melayani mahasiswa dan dosen seperti membuat surat masuk, surat keluar, menyiapkan presensi, mengatur jadwal perkuliahan, mengatur jadwal seminar proposal, jadwal seminar hasil, membuat serta mencetak kartu hasil studi mahasiswa dan kartu studi mahasiswa, memberikan pengumuman terkait perkuliahan dll.

Berdasarkan hasil observasi dan wawancara dengan staff administrasi jurusan Informatika Universitas Muhammadiyah Malang, pegawai dan beberapa tenaga kerja partime. Mahasiswa sering kali menanyakan keberadaan dosen kepada staff administrasi sebelum dilihat diruangannya. Hal ini cukup menyita waktu dan mengganggu pekerjaan, akan tetapi mahasiswa juga butuh bertanya mengenai administrasi. Sangat diperlukan sistem informasi yang dapat menginformasikan mengenai keberadaan dosen.

Penelitian terdahulu telah dilakukan untuk mengatasi permasalahan tersebut. Penelitian dari Dini Saputri Yanianti dengan judul Perancangan Prototype Sistem Informasi Keberadaan Dosen [1]. Prototype yang dirancang menggunakan metode UX Design Process dengan cara mendefinisikan produk yang dibuat, meneliti lingkungan sekitar, analisis kebutuhan, merancang prototype dan menguji prototype. Hasilnya prototype yang telah dibuat, sudah pernah ada sistem serupa yang diterapkan di jurusan namun tidak berjalan lancar karena tidak semua dosen mau untuk menginputkan data ke sistem.

Dari masalah yang telah diuraikan penelitian ini memberikan solusi agar sistem yang dibuat dapat diterima dan sesuai dengan apa yang dibutuhkan pengguna. Dengan menggunakan model prototype dalam pengembangan sistem, pengguna selalu berinteraksi dengan sistem dan memberikan masukan selama proses pengembangan [2]. Dengan demikian sistem akan terus diperbaiki hingga sistem yang dihasilkan bisa sesuai dengan kebutuhan. 


\section{METODE PENELITIAN}

Pengembangan sistem informasi pada penelitian ini menggunakan model prototype. Model prototyping merupakan proses iterative dalam pengembangan sistem dimana kebutuhan/requirement diubah ke dalam sistem yang bekerja (working sistem) yang secara terus menerus diperbaiki melalui kerjasama antara user dan analis [3].

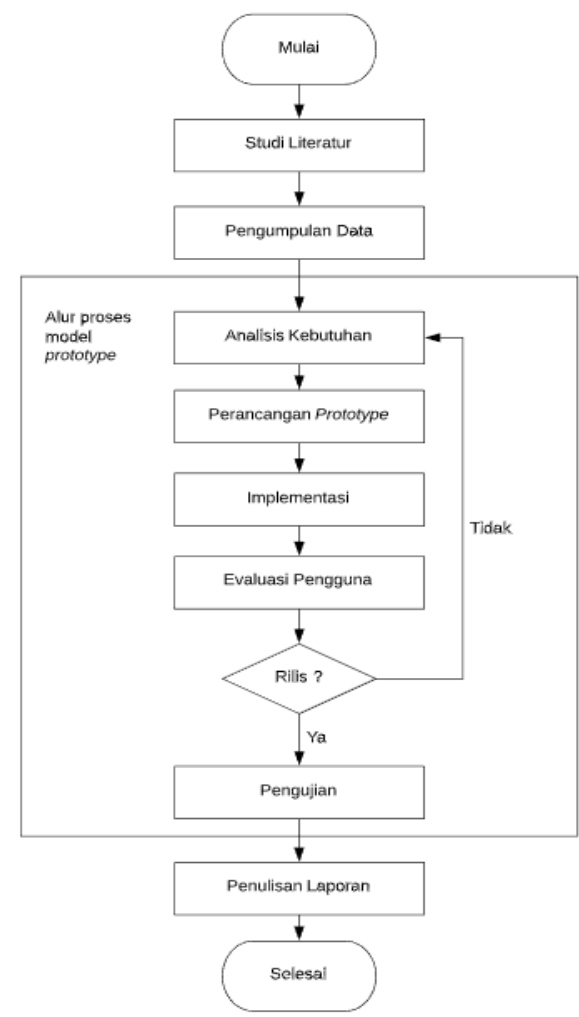

Gambar 1. Tahapan Penelitian

Pengembangan sistem informasi pada penelitian ini menggunakan model prototype. Model prototyping merupakan proses iterative dalam pengembangan sistem dimana kebutuhan/requirement diubah ke dalam sistem yang bekerja (working sistem) yang secara terus menerus diperbaiki melalui kerjasama antara user dan analis [4]. Yang membedakan penelitian ini dengan penelitian [3] adalah pada metode pengembagan perangkat lunaknya. Penelitian ini menggunakan metode pengembangan model prototype agar perangkat lunak yang dihasilkan sesuai dengan kebutuhan pengguna [5].

Tahapan pengembangan dimulai dari tahap inisialisasi, setelah tahap inisialisasi selesai dilanjutkan ke tahap perancangan prototype, setelah perancangan prototype selesai langsung dilakukan pengkodean pada tahap production, setelah tahap production aplikasi diberikan kepada pengguna dalam bentuk apk untuk dievaluasi. Hasil evaluasi akan digunakan lagi untuk inisialisasi pada versi aplikasi berikutnya. Tahapan pengembangan akan terus diulang sampai aplikasi diterima oleh pengguna.

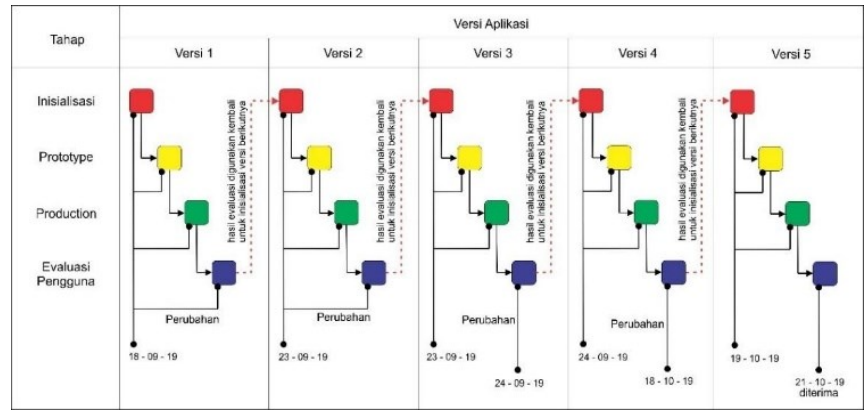

Gambar 2. Tahapan pengembangan aplikasi untuk dosen 


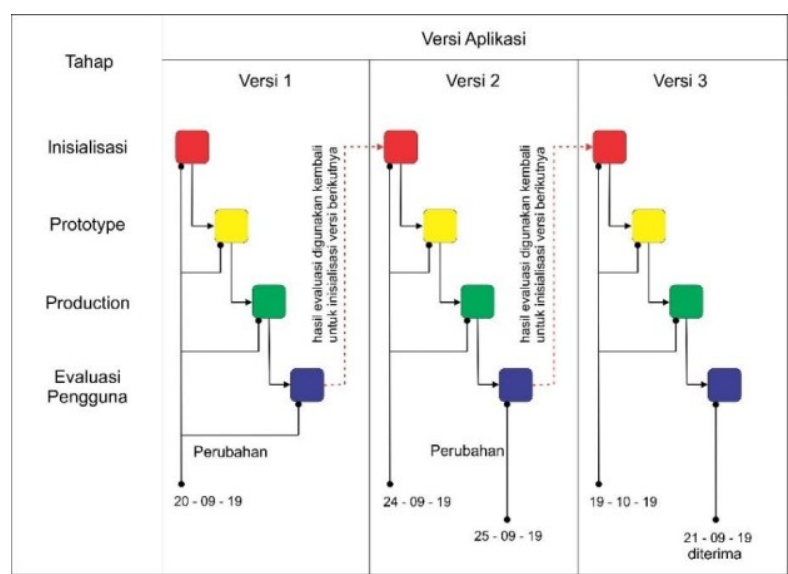

Gambar 3. Tahapan pengembangan aplikasi untuk mahasiswa

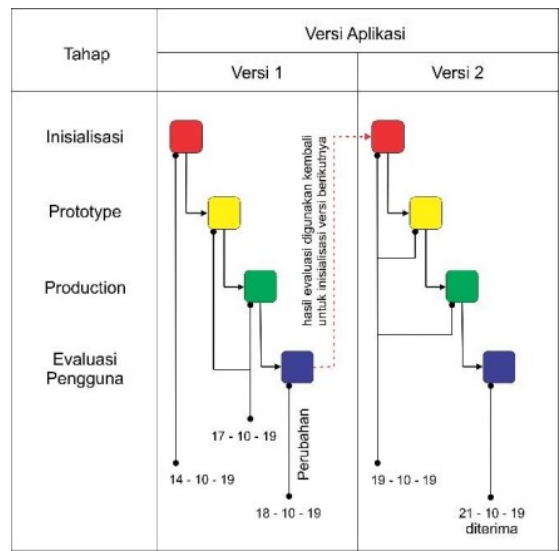

Gambar 4. Tahapan pengembangan aplikasi untuk admin

\subsection{Tahap Inisialisasi}

Pada tahap ini hasil penggalian kebutuhan dan setiap perubahan kebutuhan pengguna terhadap sistem diinisialisasikan untuk digunakan dalam pembuatan prototype.

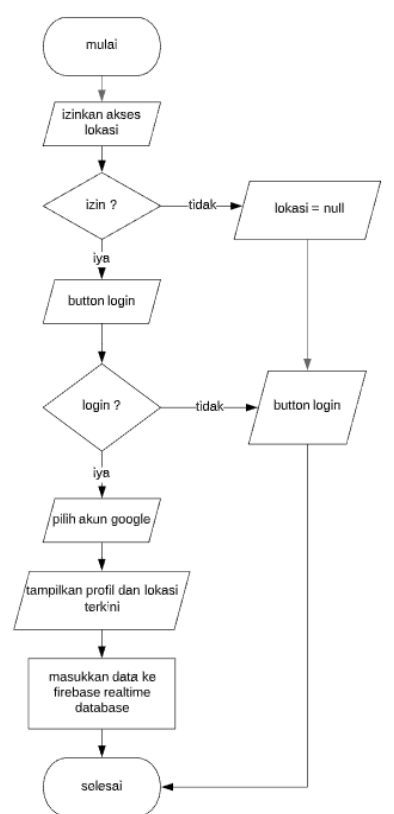

Gambar 5. Flowchart aplikasi dosen 
Gambar 5 merupakan flowchart saat aplikasi dosen pertama kali dibuka. Aplikasi akan langsung meminta izin untuk mengakses lokasi pengguna. Pengguna mengklik button login untuk login ke dalam aplikasi menggunakan akun google. Setelah login aplikasi akan menampilkan profil dan lokasi terkini pengguna. Selanjutnya data tersebut akan dimasukkan kedalam firebase.

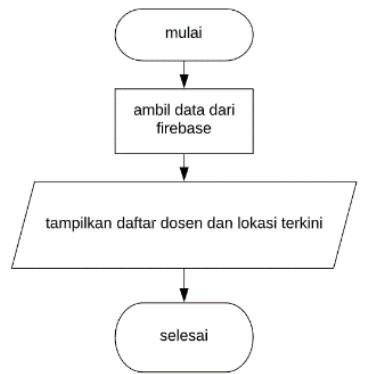

Gambar 6. Flowchart aplikasi mahasiswa

Gambar 7 merupakan flowchart aplikasi admin. Pada saat aplikasi pertama kali di buka sistem akan langung mengambil data dosen dari firebase kemudian ditampilkan kedalam daftar dosen. Untuk menginputkan data jadwal, pengguna perlu memilih salah satu dosen. Setelah itu sistem akan menampilkan form untuk menginputkan jadwal.

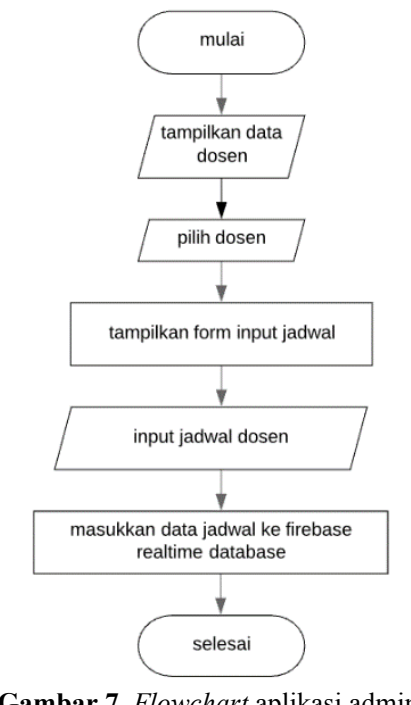

\subsection{Tahap Perancangan Prototype}

Pada tahap ini dilakukan perancangan prototype sesuai dengan hasil inisailisasi kebutuhan pada setiap versi aplikasi [6]. Dapat dilihat pada gambar 2 setiap ada perubahan kebutuhan pada tahap evaluasi. Hasil evaluasi tersebut akan diinisialisasikan dan digunakan untuk membuat prototype yang baru sesuai dengan perubahan kebutuhan.

\subsection{Tahap Production}

Tahap production merupakan tahap pengkodean sistem dari prototype yang sudah dibuat. Pengkodean sistem pada penelitian ini menggunakan kodular dengan model pemrograman Visual Programming Languange (VPL). Fitur VPL mengubah pengkodean dari bahasa pemrograman teks ke bahasa pemrograman visual berupa blok - blok kode program [4]. VPL bersifat intuitif dan mudah bagi non-programmer untuk memprogram dengan cara drag and drop [7]. Setelah pengkodean selesai, aplikasi akan langsung di export dalam bentuk apk dan dikirimkan kepada pengguna untuk dilakukan evaluasi.

\subsection{Tahap Evaluasi Pengguna}

Setelah tahap implementasi selesai, aplikasi langsung di evaluasi oleh pengguna dalam bentuk apk. Setiap ada perubahan kebutuhan oleh pengguna, pengembangan akan mengulang kembali pada tahap inisialisasi. Begitu seterusnya hingga aplikasi diterima oleh pengguna. 


\subsection{Tahap Pengujian}

Setelah aplikasi di setujui oleh pengguna, berikutnya adalah tahap terakhir dari pengembangan yaitu tahap pengujian. Pengujian pada penelitian ini menggunakan pengujian blackbox. Pengujian blackbox adalah jenis pengujian terhadap fungsionalitas input dan output dari sistem dimana penguji membuat sekumpulan kondisi input lalu dilakukan pengujian terhadap sistem sehingga dihasilkan suatu ouput yang hasilnya dapat dinilai [8].

\section{HASIL DAN PEMBAHASAN}

\subsection{Inisialisasi}

Tabel 1 dan tabel 2 menjelaskan tahap Inisialisasi kebutuhan disetiap versi aplikasi yang dibuat untuk pengguna dosen. Inisialisasi kebutuhan aplikasi untuk dosen berhenti sampai pada versi 5. Yang menandakan aplikasi versi 5 sudah diterima oleh pengguna.

Tabel 1. Inisialisasi Kebutuhan Aplikasi Dosen Versi 1 - 3

\begin{tabular}{|c|l|l|l|}
\hline \multirow{2}{*}{ Tahap } & \multicolumn{1}{|c|}{ Versi Aplikasi } & \multicolumn{1}{|c|}{ Versi 2 } & \multicolumn{1}{|c|}{ Versi 3 } \\
\cline { 2 - 4 } & $\begin{array}{l}\text { Login menggunakan akun } \\
\text { google }\end{array}$ & Perbaikan tampilan & $\begin{array}{l}\text { Perbaikan } \\
\text { tampilan }\end{array}$ \\
\cline { 2 - 4 } Inisialisasi & Tampilkan profil pengguna & $\begin{array}{l}\text { Cukup sekali login apabila sudah } \\
\text { pernah login }\end{array}$ & \\
\cline { 2 - 4 } & $\begin{array}{l}\text { Dapatkan lokasi menggunakan } \\
\text { gps }\end{array}$ & Fitur menghentikan update lokasi & \\
\cline { 2 - 4 } & $\begin{array}{l}\text { Auto input data pengguna dan } \\
\text { lokasi }\end{array}$ & & \\
\hline
\end{tabular}

Tabel 2. Inisialisasi Kebutuhan Aplikasi Dosen Versi 4 - 5

\begin{tabular}{|c|l|l|}
\hline \multirow{2}{*}{ Tahap } & \multicolumn{2}{|c|}{ Versi Aplikasi } \\
\cline { 2 - 3 } & \multicolumn{1}{|c|}{ Versi 4 } & \multicolumn{1}{c|}{ Versi 5 } \\
\hline \multirow{2}{*}{ Inisialisasi } & Perbaikan tampilan & Penambahan fitur input nomor telepon \\
\cline { 2 - 3 } & Perubahan fungsi stop gps & Penambahan fitur memperbarui jadwal \\
\hline
\end{tabular}

Tabel 3 menjelaskan tahap Inisialisasi kebutuhan disetiap versi aplikasi yang dibuat untuk pengguna mahasiswa. Inisialisasi kebutuhan aplikasi untuk mahasiswa berhenti sampai pada versi 3. Yang menandakan aplikasi versi 3 sudah diterima oleh pengguna.

Tabel 3. Inisialisasi Kebutuhan Aplikasi Mahasiswa

\begin{tabular}{|l|l|l|l|}
\hline \multirow{3}{*}{ Tahap } & \multicolumn{3}{|c|}{ Versi Aplikasi } \\
\cline { 2 - 4 } & \multicolumn{1}{|c|}{ Versi 1 } & \multicolumn{1}{c|}{ Versi 2 } & \multicolumn{1}{c|}{ Versi 3 } \\
\hline \multirow{4}{*}{ Inisialisasi } & $\begin{array}{l}\text { Menampilkan } \\
\text { daftar dosen }\end{array}$ & $\begin{array}{l}\text { Tampilkan marker dosen di } \\
\text { google maps }\end{array}$ & Tampilkan last update \\
\cline { 2 - 4 } & & $\begin{array}{l}\text { Tambah fitur refresh untuk } \\
\text { memperbarui data }\end{array}$ & Tampilkan jadwal dosen \\
\cline { 2 - 4 } & & Tambah fitur chat & Tambahkan alternatif fitur chat \\
\cline { 2 - 4 } & & $\begin{array}{l}\text { Fitur } \text { chat langsung mengirimkan } \\
\text { pesan ke nomor telepon dosen }\end{array}$ \\
\hline
\end{tabular}

Tabel 3 menjelaskan tahap Inisialisasi kebutuhan disetiap versi aplikasi yang dibuat untuk pengguna admin. Inisialisasi kebutuhan aplikasi untuk admin berhenti sampai pada versi 2. Yang menandakan aplikasi versi 2 sudah diterima oleh pengguna. 
Tabel 4. Inisialisasi Kebutuhan Aplikasi Admin

\begin{tabular}{|c|l|c|}
\hline \multirow{2}{*}{ Tahap } & \multicolumn{2}{|c|}{ Versi Aplikasi } \\
\cline { 2 - 3 } & \multicolumn{1}{|c|}{ Versi 1 } & Versi 2 \\
\hline \multirow{2}{*}{ Inisialisasi } & Menampilkan daftar dosen & Tambahkan fitur input lokasi dosen secara manual \\
\cline { 2 - 3 } & Fitur menambahkan jadwal dosen & \\
\hline
\end{tabular}

\subsection{Perancangan Prototype}

Setelah inisialisasi kebutuhan aplikasi akan langsung dilakukan perancangan prototype sesuai dengan inisialisasi kebutuhan disetiap versi aplikasi [9]. Gambar 8 menunjukkan prototype tampilan login aplikasi dosen. Gambar 9 menunjukkan prototype tampilan setelah login aplikasi dosen. Aplikasi sudah dilengkapi dengan seluruh kebutuhan aplikasi yang telah diinisialisasikan pada tabel 1. Gambar 10 menunjukkan prototype tampilan aplikasi mahasiswa menampilkan daftar dosen. Gambar 11 menunjukkan prototype tampilan aplikasi mahasiswa detail dosen. Gambar 12 menunjukkan prototype tampilan aplikasi admin menampilkan form input untuk input lokasi secara manual dan input jadwal.

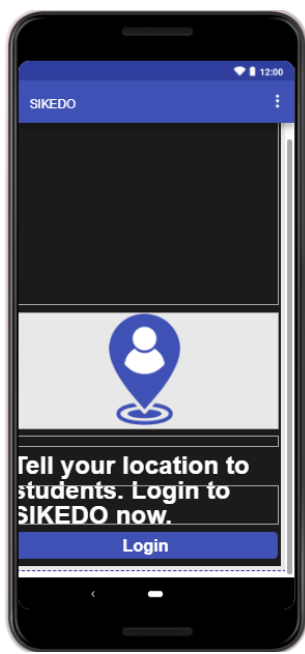

Gambar 8. Prototype tampilan login aplikasi dosen

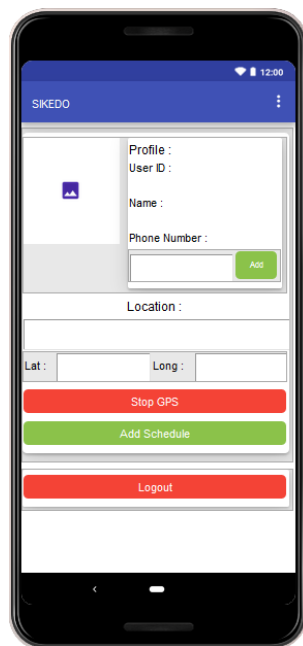

Gambar 9. Prototype tampilan setelah login aplikasi dosen 


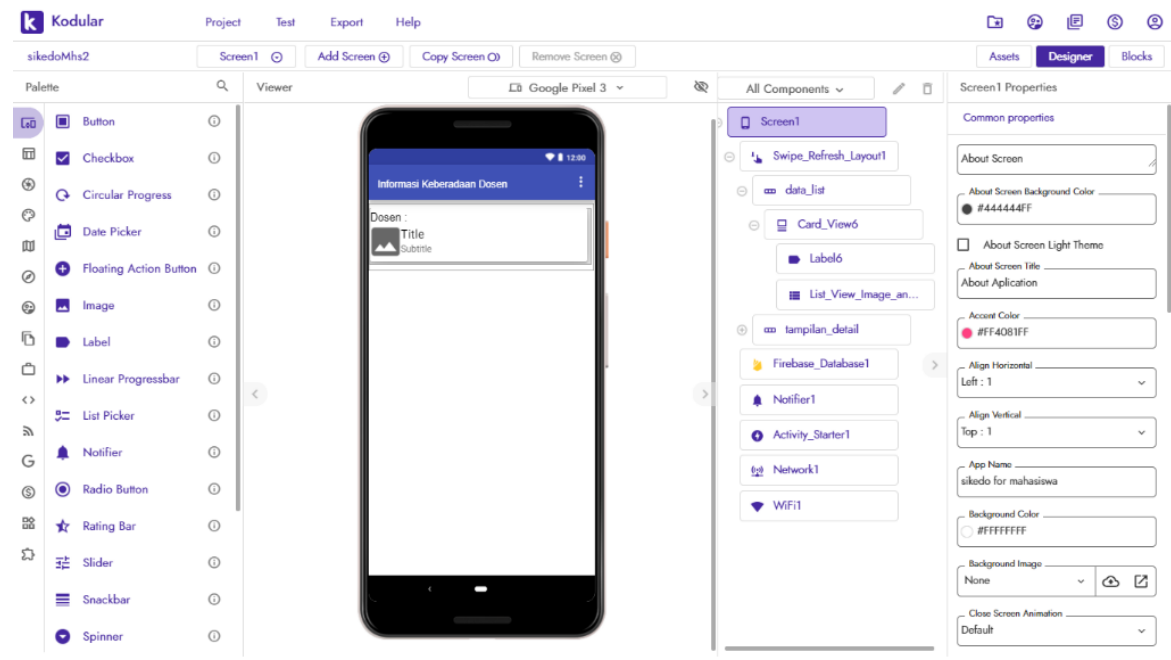

Gambar 10. Prototype menampilkan daftar dosen aplikasi mahasiswa

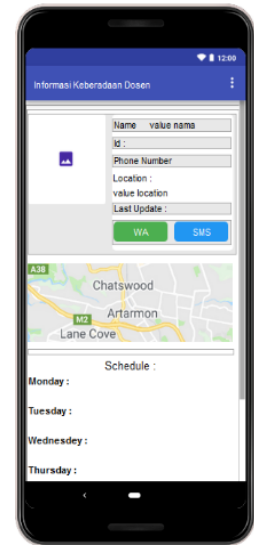

Gambar 11. Prototype menampilkan daftar dosen aplikasi mahasiswa

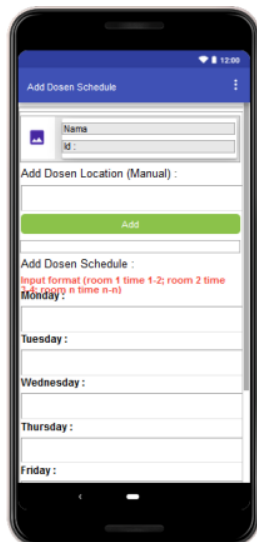

Gambar 12. Prototype tampilan form input aplikasi admin

Prototype dirancang menggunakan palette umum yang ada di dalam kodular. Kodular merupakan platform yang memungkinkan penggunanya mengembangkan aplikasi untuk perangkat android dengan menggunakan web browser dan ponsel atau emulator yang terhubung. Kodular sangat baik digunakan dalam pengembangan dengan model prototype. Setiap terjadi perubahan rancangan prototype oleh pengguna, kodular bisa dengan cepat menguji aplikasi bahkan bisa dengan cepat meng-export aplikasi dalam bentuk apk. Sehingga sangat mudah dalam menghadapi perubahan keinginan pengguna [10]. Jenis database yang digunakan adalah firebase realtime database yang disediakan oleh google. Firebase memiliki banyak fitur seperti authentication, database, storage, hosting, pemberitahuan dan lain-lain [11]. Seperti label, image, button, textbox, layout dan view list image and text. Untuk fitur login menggunakan akun google menggunakan palette firebase authentication, untuk penyimpanan data menggunakan palette firebase database dan untuk mendapatkan posisi pengguna menggunakan palette location sensor. 


\subsection{Production}

Gambar 13 menunjukkan tampilan login aplikasi dosen. Login dengan akun google sudah bisa dilakukan dan Gambar 14 menunjukkan tampilan setelah login aplikasi dosen. Aplikasi sudah dapat menampilkan profil dosen, mendapatkan lokasi, menambahkan jadwal dan fitur stop gps juga telah berjalan normal.

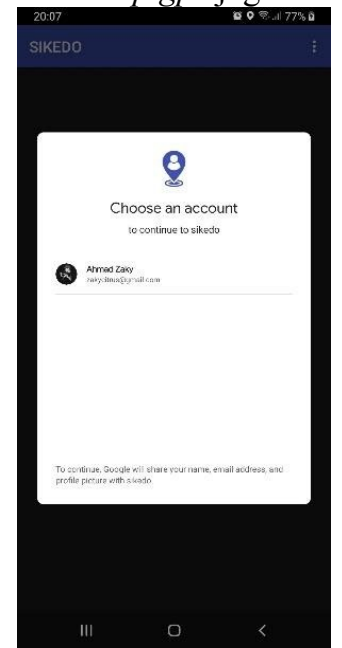

Gambar 13. Tampilan login aplikasi dosen

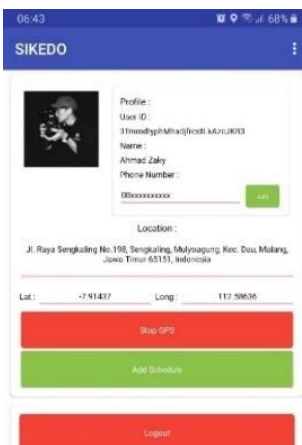

Gambar 14. Tampilan setelah login aplikasi dosen

Gambar 15 menunjukkan tampilan aplikasi mahasiswa menampilkan daftar dosen. Aplikasi sudah dapat menampilkan data dan gambar 16 menunjukkan tampilan aplikasi mahasiswa menampilkan detail dosen. Aplikasi sudah dapat menampilkan profil dosen, lokasi dosen, titik lokasi di google maps, jadwal. Kedua fitur chat juga sudah berjalan normal. 


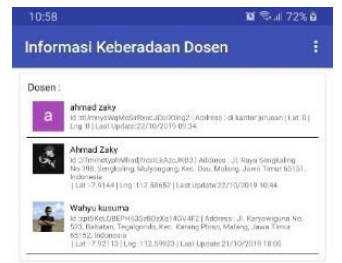

Gambar 15. Tampilan daftar dosen aplikasi mahasiswa

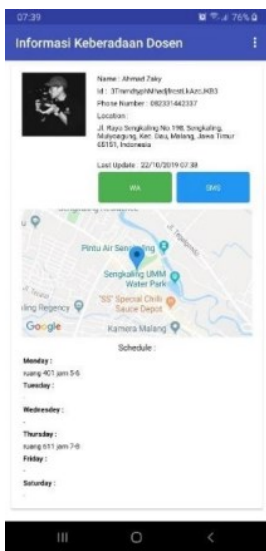

Gambar 16. Tampilan detail dosen aplikasi mahasiswa

Gambar 17 menunjukkan tampilan aplikasi admin form input. Aplikasi sudah dapat mennginputkan lokasi dosen secara manual dan sudah dapat menginputkan jadwal dosen.

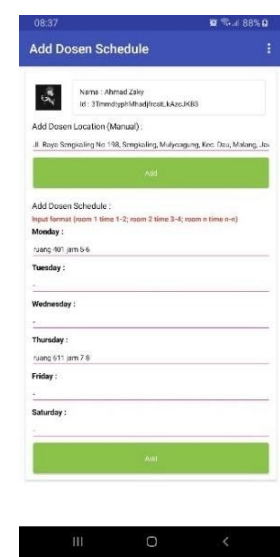

Gambar 17. Tampilan form input aplikasi admin

\subsection{Evaluasi Pengguna}

Tabel 5 dan tabel 6 menjelaskan tahap evaluasi aplikasi dosen oleh pengguna disetiap versi aplikasi. Tabel 7 menjelaskan tahap evaluasi aplikasi mahasiswa oleh pengguna disetiap versi aplikasi. Tabel 8 menjelaskan tahap evaluasi aplikasi admin oleh pengguna disetiap versi aplikasi. 
Tabel 5. Evaluasi Aplikasi Dosen Versi 1 - 3

\begin{tabular}{|c|l|l|l|}
\hline \multirow{2}{*}{ Tahap } & \multicolumn{2}{|c|}{ Versi Aplikasi } \\
\cline { 2 - 4 } & \multicolumn{1}{|c|}{ Versi 1 } & \multicolumn{1}{c|}{ Versi 2 } & \multicolumn{1}{c|}{ Versi 3 } \\
\hline \multirow{5}{*}{ Inisialisasi } & $\begin{array}{l}\text { Jika aplikasi ditutup lalu } \\
\text { dibuka pengguna tidak perlu } \\
\text { login kembali }\end{array}$ & $\begin{array}{l}\text { Tampilan terlalu Panjang, } \\
\text { cukup 1 halaman tanpa scroll } \\
\text { dan banyak ruang kosong }\end{array}$ & $\begin{array}{l}\text { Tampilan kembali pada } \\
\text { versi 1.2 kurangi ruang } \\
\text { kosong saja }\end{array}$ \\
\cline { 2 - 4 } & $\begin{array}{l}\text { Tampilan masih perlu } \\
\text { diperbaiki }\end{array}$ & & $\begin{array}{l}\text { Saat button stop gps di } \\
\text { klik, lokasi di kosongkan. }\end{array}$ \\
\cline { 2 - 4 } & Foto profil terlalu besar & & \\
\cline { 2 - 4 } & $\begin{array}{l}\text { Tambah fitur untuk } \\
\text { menghentikan Update lokasi }\end{array}$ & & \\
\hline
\end{tabular}

Tabel 6. Evaluasi Aplikasi Dosen Versi 4 - 5

\begin{tabular}{|l|l|l|}
\hline \multirow{2}{*}{ Tahap } & \multicolumn{2}{|c|}{ Versi Aplikasi } \\
\cline { 2 - 3 } & Versi 4 & Versi 5 \\
\hline \multirow{3}{*}{ Inisialisasi } & $\begin{array}{l}\text { Tambahkan fitur memperbarui jadwal agar dosen juga bisa } \\
\text { memperbarui jadwal jika ada perubahan jadwal dari dosen }\end{array}$ & $\begin{array}{l}\text { Aplikasi versi 5 sudah } \\
\text { diterima oleh pengguna }\end{array}$ \\
\cline { 2 - 3 } & Tambahkan fitur input nomor telepon & \\
\hline
\end{tabular}

Tabel 7. Evaluasi Aplikasi Mahasiswa

\begin{tabular}{|c|l|l|l|}
\hline \multirow{2}{*}{ Tahap } & \multicolumn{1}{|c|}{ Versi 1 } & \multicolumn{1}{|c|}{ Versi Aplikasi } & \multicolumn{1}{|c|}{ Versi 2 } \\
\cline { 2 - 4 } & $\begin{array}{l}\text { Menampilkan marker lokasi } \\
\text { dosen di google maps }\end{array}$ & $\begin{array}{l}\text { Perlu ditambahkan last update untuk } \\
\text { mengetahui kapan tehakhir kali dosen } \\
\text { melakukan update }\end{array}$ & $\begin{array}{l}\text { Aplikasi versi 3 } \\
\text { sudah diterima oleh } \\
\text { pengguna }\end{array}$ \\
\cline { 2 - 4 } & $\begin{array}{l}\text { Menambahkan fitur refresh } \\
\text { halaman untuk } \\
\text { memperbarui data }\end{array}$ & $\begin{array}{l}\text { Menambahkan fitur chat alternatif } \\
\text { lain jika dosen tidak sedang } \text { online }\end{array}$ & \\
\cline { 2 - 4 } & Menambahkan fitur chat & $\begin{array}{l}\text { Langsung mengirimkan pesan ke } \\
\text { nomor telepon dosen yang } \\
\text { bersangkutan }\end{array}$ & \\
\cline { 2 - 4 } & & Tampilkan jadwal dosen. & \\
\hline
\end{tabular}

Tabel 8. Evaluasi Aplikasi Admin

\begin{tabular}{|c|l|l|}
\hline \multirow{2}{*}{ Tahap } & \multicolumn{1}{|c|}{ Versi Aplikasi } \\
\cline { 2 - 3 } & \multicolumn{1}{|c|}{ Versi 1 } & \multicolumn{1}{|c|}{ Versi 2 } \\
\hline \multirow{4}{*}{ Inisialisasi } & $\begin{array}{l}\text { Perlu ditambakan fitur input lokasi dosen secara manual sebagai } \\
\text { alternatif jika dosen sedang offline atau tidak ada koneksi internet. }\end{array}$ & $\begin{array}{l}\text { Aplikasi versi 2 sudah } \\
\text { diterima oleh pengguna }\end{array}$ \\
\cline { 2 - 3 } & $\begin{array}{l}\text { Perlu ditambakan fitur input lokasi dosen secara manual sebagai } \\
\text { alternatif jika dosen sedang offline atau tidak ada koneksi internet. }\end{array}$ & $\begin{array}{l}\text { Aplikasi versi 2 sudah } \\
\text { diterima oleh pengguna }\end{array}$ \\
\hline
\end{tabular}

\subsection{Pengujian Blackbox}

Pengujian blackbox adalah jenis pengujian terhadap fungsionalitas input dan output dari sistem dimana penguji membuat sekumpulan kondisi input lalu dilakukan pengujian terhadap sistem sehingga dihasilkan suatu ouput yang hasilnya dapat dinilai [12]. Hasil pengujian sistem informasi keberadaan dosen terhadap 11 poin kebutuhan fungsional aplikasi, menyatakan sistem telah berjalan sesuai dengan yang diharapkan dan dapat dioperasikan dengan baik. Hasil pengujian dapat di lihat pada tabel 9.

Tabel 9. Hasil Pengujian

\begin{tabular}{|l|l|l|l|}
\hline No & Kebutuhan & Pengguna & Status \\
\hline 1 & Dosen masuk ke sistem menggunakan google account & Dosen & Success \\
\hline
\end{tabular}




\begin{tabular}{|l|l|l|l|}
\hline 2 & Auto input update lokasi keberadaan melalui device pengguna & Dosen & Success \\
\hline 3 & Fitur menghentikan gps untuk menghentikan update lokasi & Dosen & Success \\
\hline 4 & Fitur input nomor telepon & Dosen & Success \\
\hline 5 & Fitur input jadwal & Dosen & Success \\
\hline 6 & Sistem menampilkan informasi keberadaan dosen secara real time & Mahasiswa & Success \\
\hline 7 & Sistem menampilkan marker lokasi dosen pada google maps & Mahasiswa & Success \\
\hline 8 & Mengirim pesan & Mahasiswa & Success \\
\hline 9 & Sistem menampilkan jadwal dosen & Mahasiswa & Success \\
\hline 10 & Fitur input jadwal dosen & Admin & Success \\
\hline 11 & Fitur input lokasi dosen secara manual & Admin & Success \\
\hline
\end{tabular}

\section{KESIMPULAN}

Berdasarkan hasil penelitian yang di lakukan, dapat diambil kesimpulan sebagai berikut :

1. Penelitian ini telah berhasil menerapkan metode pengembangan prototype untuk pengembangan Sistem Informasi Keberadaan Dosen. Dengan tahapan pengembangan dimulai dari inisialisasi, perancangan prototype, production, evaluasi pengguna dan pengujian. Pengembangan aplikasi untuk dosen memerlukan 5 kali iterasi sampai aplikasi diterima oleh pengguna sedangkan aplikasi untuk mahasiswa membutuhkan 3 kali iterasi sampai diterima oleh pengguna dan aplikasi untuk admin membutuhkan 2 kali iterasi sampai diterima oleh pengguna.

2. Pengujian sistem terhadap 11 poin kebutuhan fungsional berhasil dilakukan dan diperoleh hasil yang sesuai dengan kebutuhan.

Dibawah ini terdapat beberapa saran untuk peningkatan aplikasi :

1. Aplikasi perlu ditingkatkan lagi agar aplikasi dapat berjalan di background sehingga dosen tidak perlu lagi membuka aplikasi untuk meng - update lokasi. Aplikasi meng - update lokasi secara realtime setiap pengguna berpindah lokasi.

2. Aplikasi perlu ditingkatkan lagi agar aplikasi dapat menampilkan data lokasi dosen berdasarkan pada jadwal, jam dan ruang kuliah. Sehingga data lokasi dosen hanya diinputkan 1 kali setiap semester.

\section{UCAPAN TERIMAKASIH}

Terima kasih disampaikan kepada seluruh pihak di Universitas Muhammadiyah Malang dan Program Studi Informatika pada khususnya atas dukungan dalam pemberian data dan informasi yang dibutuhkan oleh peneliti guna terselesaikannya penelitian ini.

\section{REFERENCES}

[1] S. Aswati, N. Mulyani, Y. Siagian, and A. S. Edisi2, "Peranan sistem informasi dalam perguruan tinggi," Jurteksi Royal Edisi 2, 2015.

[2] M. I. Wahyuni, ED, "Perancangan Prototype Interface Sistem Informasi Keberadaan Dosen,” Jurnal Tekno, vol. 14 no. 1 , pp. 11-16, 2020.

[3] R. Fauji and A Rahmatulloh, "Implementation Of Global Positioning System As A Location Monitoring Media For Final Project Guidelines On Android-Based Applications," Jurnal Transformatika, vol. 16, no. 2, pp. 169-174, 2019.

[4] S. Boell and D Cecez-Kecmanovic, "What is an information system?," in 48th Hawaii International Conference on System Sciences, 2015.

[5] S. Mulyani, Metode Analisis dan perancangan sistem. 2017.

[6] I. Hooda and RS Chhillar, "Software test process, testing types and techniques," International Journal of Computer Applications, vol. 111, no. 13, pp. 975-8887, 2015.

[7] S. Hsu, Y. Lou, and C. Sun, "Block Shelves for Visual Programming Languages," arXiv preprint arXiv:1605.00807, May 2016.

[8] M. S. P. Aditama, S. A. Wicaksono, and F. Pradana, "Pembangunan Sistem Informasi Kenaikan Jabatan Fungsional 
Dosen Universitas Brawijaya," Jurnal Pengembangan Teknologi Informasi dan Ilmu Komputer, vol. 2, no. 10, pp. 3538-3544, 2018.

[9] C. Chandramita, "Metode Prototyping Dalam Pengembangan Sistem Informasi.".

[10] H. Kang, J. Cho, and H Kim, "Application study on android application prototyping method using app inventor," Indian Journal of Science and Technology, vol. 8, no. 18, 2015.

[11] G. Payara and R Tanone, "Penerapan Firebase Realtime Database Pada Prototype Aplikasi Pemesanan Makanan Berbasis Android," JuTISI (Jurnal Teknik Informatika dan Sistem Informasi), vol. 4, no. 3, pp. 397-406, 2018.

[12] T. Wahyuningrum and DD Januarita, "Implementasi dan pengujian web e-commerce untuk produk unggulan desa," Jurnal Komputer Terapan, vol. 1, no. 1, pp. 57-66, 2015. 